\title{
Past Buoy Lines: Exploring Metaphors, Boundaries, and Poetic Possibilities in Giftedness Research
}

\author{
Pamela Richardson \\ The University of British Columbia
}

\begin{abstract}
This piece is a poetic and narrative inquiry (Leggo, 2004) into the conceptual, physical, and emotional underpinnings of research methodology in the field of gifted education. First, the author explores the metaphorical possibility of swimming rather than standing in the field of inquiry and how relationships to self, environment, and other would shift in ways potentially commensurate with the task of researching giftedness. Then, responses to a questionnaire asking researchers about their understandings, hopes, and fears in the use of "nontraditional" methodologies in the field of gifted education are explored through the creation of poetic aphorisms.
\end{abstract}

During the summers of my childhood I spent many days at public beaches. This was before they closed for health reasons - before E. Coli and fear of UV rays, when slathering on coconut oil was still an option. I was born near the lakes of Northern Ontario: Nipissing, Nepewassi, and Wanapetei. This is where my mother grew up and where my parents met. My maternal grandmother could swim a mile across the lake and back. I too was a good swimmer, more coordinated in water than on land it seemed to me. The summer Lady Diana married Prince Charles, her train filling the aisle in a river of silk and brocade, I watched on a small black and white television at my grandparent's cabin on the west arm of Lake Nipissing.

My parents moved south to Toronto in 1978, but every summer we escaped our sprawling suburb and headed north, trading the landscape of sidewalks, lawns, and sprinklers for rocks, trees, and lakes. Along HWY 69 we would stop in the small community of Pointe au Baril (Gun Barrel) to purchase blueberry pies, and then further on, where the French River meets Georgian Bay, we would stop at the French River Trading Post for ice cream and First Nations memorabilia. By the age of 7, I owned a small tomahawk made of wood and stone, as well as a brown plastic doll with black braids and a tawny dress with a zigzag hem. Soon after I added a leather rattle on a stick to my collection. I loved the very mention of French River as I associated it entirely with this store. Twenty years later when my grandfather, separated from my grandmother, 
moved from his motel into a trailer on the banks of the French River itself, all I could conjure up were the towering aisles of this road-side gift shop of memory with the totem pole out front.

Many beaches of my memory look like this: A parking lot surrounded by trees, then grass, which gives way to patches of grassy sand, then to an unbroken expanse of sand. The sand is brownish grey, dotted with bits of calcite and smooth black stones - an unassuming landscape, the colour of pigeons and seagulls. Except, when I crouched down and scooped a palm of sand, it twinkled of pulverized granite - specks of green, yellow, and red. And, if I tilted my head to the shore, the slick tangles of sea-grass amassed along the water's edge looked as strange as the shorn locks of a giant sea creature. The water stretched not to the horizon, but to the smudge of an uneven tree line drawn along the opposite shore. And always, the lake reflected the sky in shade and motion - from nickel to sapphire. No one word describes the colour of the water. We say blue, but this is maybe our notion of water reflected back at us.

Mostly, the waves rolled in at low frequencies. Waves that reached my knees generated excitement of Elvis proportions. I would squeal and jump, writhe my body. Sometimes I could see my toes even while standing waist deep, especially in lakes near the Sudbury nickel mines. This was not a good sign as it meant the water was too acidic and could not sustain plant life. This was my first lesson about the murkiness of real life. On the beach, lifeguards in high red and white chairs surveyed swimmers within an area designated by a buoy line.

Other than grass, rocks, sea-grass, sand, water, lifeguard chairs staffed by lifeguards, and buoy lines, what made it a beach was the presence of other beach-goers surrounded by their beach-gear: nylon and aluminum folding chairs and worn cotton blankets, blue and orange coolers, barbeques, plastic pails and shovels, striped inflatable beach balls, oversized terry cloth towels, neon bottles of suntan lotion, giant parasols, Kodak instamatics. Everywhere, bodies in bikinis, one-pieces, swimming trunks, and Speedos. Families spaced out as strategically as small villages along the shore, allowing as much privacy and access to amenities as the terrain permitted. All this together with the warm sun on my skin signaled I was at the beach.

I know that some people went to secret swimming holes. Places hid behind tangled bushes, down imperceptible trails. Places that required work to reach. Places that due to their remoteness limited the amount of stuff one could carry in. Places with rock outcrops to jump from and maybe ropes from which to swing. Places with no signs to point the way or signal how to behave. These were not the beaches of my experience. My beaches had large signs: signs that denounced dogs, spitting, campfires, drinking, and other unruliness. My beaches had names taken from the local First Nations group. And, my beaches of memory had buoy lines.

Ropes of primary red, yellow and blue, strung out plastic buoys.

Nylon arms reach towards the shore.

Children scream, lifeguards survey,

water surges in and out of bounds,

promises to carry us away.

Maybe it was that age when all of society started to seem problematic; maybe it was the year my parents started to do everything wrong. Maybe I had gone as far as I could with the underwater handstand and the dead man's float, but one day when I grabbed onto the buoy line it struck me that it was all the same water. The lifeguards from their perches could tell me to not swim on the other side, but it did not matter because the water flowed regardless. In that case one side was as good as the other, and the buoy line was a contrivance, its utility a chimera. It bothered me that no one else seemed to question the arbitrary nature of the line. Even though I was 
interested in swimming outside the line I was worried about getting in trouble. I was stuck between revelation and propriety. I tested the line, but did not seriously swim over it. It did not change the fact that I got whistled down by the lifeguard for messing around.

Like a fence around a school-, back-, or prison- yard, buoy lines at a beach designate and enclose the leisure space. Two parallel lines connected by a third along the top reach like arms towards the shoreline. This is the top plane of an imaginary watery cube, homage to a swimming pool (itself a simulated lake), and the metaphor of, or reference to, a fence. Buoy lines delineate parameters, signal a degree of surveillance of these parameters and lay out limits for inclusion and exclusion. The lines are limited in their flexibility. They are fixed to the shore at a point that permits a safe swimming experience. They exist ostensibly to protect swimmers from the flowing nature of water, to provide information about the depth of the water, and to enable easy surveillance by lifeguards. While at the beach, all swimmers are expected to stay together inside the buoy lines. To stay together promises safety. To transgress the lines signals risk. On the inside of the buoy lines: family and familiarity, endless opportunities to demonstrate one's skills at the underwater handstand or the dead-man's float, and time to meditate on clouds while floating on one's back, avoiding the bodies of others. On the far side of the buoy lines: unknown depths, maybe death, and loss of self. What I recall is that I always felt compelled to swim right up along the edge of the buoy lines. If possible, I loved to swim right on top of the buoy line, straddle it, stand on it, summersault around it. I am sure I am not the only one.

\section{Mixing Methodological Metaphors: Swimming in the Field}

All of the papers in this special issue offer broadened possibilities for the research and education of gifted individuals, either in terms of types of research data collected (Porath), populations studied (Fogel), cultural narratives mined (Ngara), and pedagogies employed (Lai). In this piece, I explore how metaphors germane to our inquiry processes emerge from our embodied experiences, and how by shifting metaphors we may open up increased possibilities for imagining, knowing and being, particularly with regards to educational research. I then draw connections specifically to giftedness and to the researching of individuals perceived as gifted and explore how our metaphors shape our knowledge and relationships to the subject. I started this paper with a narrative exploration of my experience of lakes as a child. Out of this process emerged a central metaphor, the buoy line as boundary, which I explore further on. While I believe that our knowledge of water and experiences of swimming may provide useful metaphors to explore our relationship with research methodology, I would like to begin on terra firma by exploring the experience and notion of field - as in field of grass and field of inquiry. Differences between walking in a field and swimming in a lake are many and, as metaphors, both enable different epistemological and imaginative possibilities. The following poem explores one morning walk through a field behind my house. In it I explore my physical experience in the field whilst caught in a moment of deep attention, and how connections between natural and cultural phenomena become visible and even merge in this particular poetic space of mind.

This morning as I

trekked sun-blinded

across a field of delphinium,

the black iridescence of

a slug caught my eye. 
Sole of rubber

boot suspended -

I stood and mimed her

impossible slowness,

thick and unctuous.

I wanted to merge with her

then, be tucked

in a sweep of tall grass.

Sly as a comma

in a José Saramago novel.

Time slips past like

the slow hand

on the clock.

Like molasses in January,

my mom would say,

when January lasted

half the year and

molasses made every dish

a French-Canadian specialty.

When I got back,

plums, small as kalamatas,

beckoned me to pick them

before they fell.

I could only reach a few.

Because of embodied experiences of fields, organized into knowledge through millennia of human interaction, the metaphor of field of inquiry invites particular kinds of conceptual movement and activity (for extensive exploration of how cognitions emerge from embodied experiences through the language of metaphors, see Lakoff \& Johnson, 1980, 1999). As with everything, fields (of grass) are experienced physically across four dimensions, the three spatial dimensions of length, width, height, and the fourth, time, which is intrinsic to experiencing the others. This is in tandem with the five senses, which also contribute their own perceptual information to what we can know about fields. By existing through our body and our senses along these dimensions we realize ever shifting perspectives and relations, as organized within and through shared knowledge of fields.

I propose that fields invite, in particular, an awareness of lateral spaces, trajectories, and surfaces. They are flat, open, and stable. It is likely one would traverse or journey across a field. What else does one do in a field? When setting out, one must survey the terrain if he or she wishes to forge new pathways. In this way, fields provide the perfect context for an argument as expressed through the "journeying" metaphor, as in: we've covered some ground, but you strayed from the line of the argument, and now we are going in circles (Lakoff \& Johnson, 1980). Because they are flat and stable, fields are also good places for building structures, which, like arguments (and theories), must have strong foundations. Thus, journeying and building are both likely to occur in a field. In addition, fields are "often bounded by fences or hedges" (see definition in New Oxford American [Software], 2005-2007). They are bounded areas. Like fields, humans also experience the world from within a bounded container. This container is known as a body and is wrapped in skin. Thus, we are able to differentiate the inside from the outside of our body. This basic human experience of containment and separateness from other 
bounded entities leads us to perceive most objects and concepts in similar terms. Thus, one can say whether something is inside or outside of the field. It is possible to travel between fields, but one must surmount barriers. Buoy lines are also a type of fence and create the sense of a bounded container. The differences between a fence and buoy line are limited, except for the significant fact that buoy lines float.

Field-based metaphors thus reify our experiences of fields as places that invite lateral movements across surfaces until a limit is reached. Activity too far above or below the surface is not always welcome or possible when toiling in a field. We must, for starters, be careful not to get into a rut. We can dig in our heels, work in the trenches (field warfare), and stake your claim (mining the field), but should avoid bogs because getting bogged down is deadly-best to just stay in the clear. If possible seek higher ground (hillock) to gain some perspective, but do not get too used to rarified air (ivory tower structures); it is still important to get your hands dirty on occasion. Some of us who have our head in the clouds should really just come back down to earth. If we have lots of time or resources, we can dig deeper, even go underground for a while and become a subversive. Subversion is an essential act when working in a field: from the old French, vertere meaning to turn (now the French verser and related to the poetic term verse) - to subvert is the work of the plowman turning a row or a line (New Oxford American [Software], 2005-2007). But subversives, while necessary to growth in any field, are not always appreciated. They tend to like upheaval and things can get mucky.

While our bodies exist upwards and downwards through physical height, and we go further upwards through structure or downwards through the archeological acts of digging and excavating, I would argue that in most fields we experience this dimension less frequently, positively or consciously than the other dimensions. Beyond the problems the subversives down below or ivory tower dwellers up above face, the third dimension is the vertical axis we immediately occupy, it is the air we breathe down into our lungs, and it is the earth directly beneath our feet, it is located wherever we stand. The physical experience cum metaphor I would like to highlight therefore is this third dimension of depth. I believe that it is here we most radically shift and benefit when we head out of the field and into the lake.

\section{Giftedness and the Third Dimension}

Here is an artful example of how shifts in spatial relations lead to new ways of being and knowing. In Orson Scott Card's (1985) science fiction classic, Ender's Game, Ender, a profoundly gifted 6-year-old boy, trains at a military academy with other children in order to save Earth from imminent destruction at the hands of an alien species known as the Buggers. Ender excels beyond those twice his age due to his quick grasp of the implications of working in low and null gravity conditions. He realizes that the old rules of down and up need not apply; that what was considered "up" in normal gravity could now be "front" or "back" or whatever he chooses. This realization, at first disorienting, quickly becomes his strength.

For a sickening moment he tried to retain his old up-and-down orientation, his body attempting to right itself, searching for the gravity that wasn't there. Then he forced himself to change his view. He was hurtling towards a wall. That was down. And at once he had to control himself. He wasn't flying, he was falling. This was a dive. He could choose how he would hit the surface. (Card, 1985, p. 56) 
By the age of 12, Ender has obliterated the entire Bugger species all the while believing he was playing training games to prepare him for a future battle. The whole of humanity is elated. They celebrate victory, claim Ender as their saviour, and prepare to colonize the Buggers' now vacant planet. Ender though, having fully integrated the implications of spatial re-orientation, is under no compunction to follow their upwards and outwards trajectory. Grasping the implications of the violence he wrought on this unique species, he falls instead into a deep depression. Eventually, he makes contact with the last surviving member of the race, a queen who has remained in pupae waiting for him to arrive. Ender receives her story and writes it out for others to know. This story becomes a classic religious text for humanity, akin to a bible, and Ender becomes known as the Speaker for the Dead. In this way, he masters the art of true subversion: the turning up of the underground through the creation of verse, and he is able to reorient himself in relation to others for radical ethical gain.

While from above water and buoy lines may appear as a field-like, two-dimensional plane, when we are in the lake we gain a new, and maybe more telling, perspective. Water as a medium invites immersion and submersion (from Latin mergere, meaning 'to dip' into- or under-), and thus movement "through" its own self, not only across its surface. We are relatively conscious of water as we move through it. While we are, for example, always submerged in air, we do not think about it much, and most of us do not have experience with a range of different physical possibilities in this dimension-gymnasts would be an exception. Children too, maybe. Typically we are head up, feet down, or lying prone, and our language reflects and reinforces this physical reality. It is good to keep our feet on the ground and our head up. Being head over heels is definitely an altered state. I would like to argue that being in water, and metaphors about water, reanimate our awareness of the ignored dimension of depth. Due to the relative density of water as compared to air we now have the capacity to radically reorient ourselves along this axis. Gravity is less of an issue. The medium invites play, new ways and perspectives not easily possible in a field. We can be horizontal, upside down, right side up, or on an angle, like synchronized swimmers. We move smoothly from one position to the next. By moving through water we gain expertise in the depth dimension, the dimension that connects our head and heart, and the line that connects through us to the sky and the earth. Water, as a metaphor, enables what Ender, the 12-year-old boy who saved Earth, acquired - new and useful possibilities for how we orient ourselves in the world and in relationship to others.

If, with regards to understanding gifted education, we take the position of lifeguards in the high up chair then we only know who is in and who is out of bounds. We see the field as a two-dimensional plane, we forget that air, like water, flows; we forget we are always submerged; we forget that the air in our lungs was just now outside of us and is just now once again inside; we forget that inside and outside are actually conceptual conveniences, in that they depend on perspective. Lakoff and Johnson $(1980,1999)$ showed that our understandings of boundaries are structured through metaphors; this means that they are contingent and can shift through language use.

Inquiry into the nature of giftedness, genius, and creativity should by definition be at the limit and beyond of methodological innovation. It should ignore the buoy line, only noticing it to swim past it. Or, it should make as its primary business understanding the role of the buoy line in the face of the flowing nature of water. In this type of inquiry the buoy line is the subject. It is possible that under such laser type scrutiny the line would dissolve and this is another way of seeing our way clear. By locating oneself appropriately, by experiencing the implications of one's location in the sea of academia similarly to how gifted individuals are positioned, in say, 
schools, the field becomes its own best subject. If instead we take the position of lifeguard in the high up chair, we risk betraying our subject, by trading experience for a distant view. This betrayal, while couched in metaphor, is literal. I submit that all us who swim in the sea-students, teachers, scholars - experience distance from the subject, consciously or not, to different effects, and this weakens our capacity to know, and weakens our imaginative possibilities. Maybe if, like me, you have spent most of your time at public beaches, I invite you to now join me for a swim at a lesser-known swimming hole. Here is my invitation:

Dearest Inquirer,

We cannot make claims about giftedness by squinting through binoculars from inside the buoy lines at what lies beyond. How can one know about exceptionality from the vantage point of the cultures most often tread waters? Please join me for a poetic excursion where we dip below the surface and swim towards new possibilities.

Sincerely,

An Inquirer.

\section{Islands in the Stream: Voices from the Field}

In the following section, researchers involved in Gifted Education and Psychology share their experiences, hopes, and fears in using so-called non-traditional methodologies in their research. Through an email questionnaire I asked the following questions: (a) What is your understanding of non-traditional research methodology in the field of gifted education and psychology? (b) Please identify the non-traditional research methodology(ies) that you have employed; (c) In consideration of the many aspects of the research process, the various stakeholders and the larger knowledge building process in the field, what do you consider to be the specific benefits derived from employing non-traditional methodologies? (d) Given the same as above, what do you consider to be specific challenges? (e) What are your hopes in employing such a methodology? and (f) What are your fears?

Through these questions I hoped to explore the following: Where are the current boundaries in this field? How do notions of boundaries figure in researchers' work in gifted education? What does it mean to go out of bounds in this field? Respondents defined "non-traditional" for themselves, and while some had little sense of what the term might entail or questioned the validity of such a category, others situated their work entirely in these terms. When respondents left the question unanswered, the absence of words is also taken to mean something and is represented. The words and silences of researchers in the field of gifted education are here collected and represented in a curatorial fashion. My intent is poetic excursion into the language of community norms and epistemological assumptions couched in talk and silence about methodology and knowledge making. I hoped to give a sense of how researchers imagine and experience methodological buoy lines and situate themselves in this regard. Too, I wanted to take a swim beyond the line and invite readers along. Out of 162 questionnaires, 27 researchers respondedperhaps a perfect number for an intimate poetic gathering. All respondents represented here have contributed to scholarship in the field through peer-reviewed articles and conference presentations. Marked diversity exists in terms of experiences, from graduate students to scholars regarded as eminent, and, diversity in background is also present, including researchers from Australia, Canada, Western Europe, and the United States. 
In working with the responses, in reading and re-reading them, in playing with and contemplating the words, what emerged was something akin to aphorisms, or words of wisdom and warning. I like this term "aphorism" for several reasons. An aphorism is "a short, pithy statement containing a truth of general import" ("Aphorism," Harper, 2001). In this way, an aphorism strives to make a truth claim and exists in the world with a particular weight and authority. This is also what academic researchers work for. Aphorism, based on the Greek word aphorizein, meaning to "mark off, divide, bound, limit, separate," has the same root as horizon. In this way an aphorism is a bounded entity like a field, a beach with buoy lines, or a human being. It is seemingly impossible to avoid notions of limits and separation when speaking - so embedded they are in our experience of language and being human. The aphorism, then, represents through its form as well as its content a particular approach to knowing and being in the world. Eliot Eisner (2005) said:

\begin{abstract}
In talking about experience and its relationship to the forms of representation that we employ, I am not talking about poetry and pictures, literature and dance, mathematics and literal statement simply as alternative means for displaying what we know. I am talking about the forms of understanding, the unique forms of understanding that poetry and pictures, literature and dance, mathematics and literal language make possible. (p. 155)
\end{abstract}

As a prelude to the aphorisms I offer the following section of a poem by Margaret Atwood (2006), which speaks to the experience of separation though naming, labels, and language. Atwood's poem provided the imaginative leaping off place for my own poetic exploration. This is written alongside in italics.

The Animals Reject their Names and Return to their Origins: Part I (M. Atwood)

Sea Creature Methodology

It was the bear who began it. Said,

I'm getting out from under.

I am not Bear, l'Ours, Ursus, Bär

Now we cast our lines

into the Sea of Possibility,

fish for revelation.

or any other syllables

you've pinned on me.

Forget the chateau tapestries

Patient, patient,

trusting, trusting.

In which I'm led in embroidered chains.

And the scarlet glories of the hunt

that was only glorious for you,

you with your clubs and bludgeons.

Now we sink

below the surface, swim past buoy lines,

be uncharted ones,

be untouched islands, archipelagos like ellipses

on the tide, rare points.

Forget the fairy tales, in which I was

your shaggy puppet, prince in hairshirt, surrogate

for human demons.

We don't re-name

or claim a new 
I'm not your coat, rug, glass-eyed trophy head, plush bedtime toy, and that's not me in outer space with my spangled cub.

I'm not your totem; I refuse to dance in your circuses: you cannot carve my soul in stone.

I renounce metaphor: I am not child-stealer, shape-changer, old garbage-eater, and you can stuff simile also: unpeeled, I am not like a man.

I take back what you have stolen, and in your languages I announce I am now nameless.

My true name is a growl. we become deep sea translucence - slippery, stretching, un sidedness, round and roundness,

a many-eyed sea creature: we see creation in ourselves.

We shimmer and open up, our hearts on the outside, hollow, ineffable now

the inner glow comes through.

\title{
Poetic Aphorisms
}

The following poetic aphorisms are sometimes achieved while at other times they are near-aphorisms, and near poetry, on the boundary of the quality that could perhaps lend them the power of a truth claim or the impact of artistry. This seems to me appropriate for how voices coexist, collude, and collide to create knowledge through culture. Not all voices are equally positioned or equally suited to the form demanded. In working this way with the responses I draw inspiration and courage from scholars such as Thomas Barone (2008) who said,

\begin{abstract}
Although I do occasionally feel the need for research texts that guide me towards conventionally valid propositions, I also appreciate texts that offer varied (sometimes even conflicting) renditions of educational phenomena. These are narrative constructions with the power to lift the veil of conventionality from my eyes as they subtly raise disturbing questions about the necessity and desirability of comfortable, familiar educational discourses and practices. These are the products of an educational research that refuses closure to redirect an ongoing conversation. (p. 465)
\end{abstract}

The following words are more or less direct quotes, only occasionally have they been adjusted grammatically for length and poetic effect. Each section begins with the question as posed on the questionnaire. Sometimes the entire response to the question is presented; other times the words have been de-contextualized from longer passages and a central idea represented. In reading through the entire sequence of responses you will by the end have heard from all 27 respondents although not all are represented in each section. Between each section are brief interludes where the many forms of so-called non-traditional inquiry in which the respondents have engaged are listed. 
What is your understanding of non-traditional research methodology in the field of gifted education and psychology?

i.

One that makes a difference

in the lives of children

in an educational setting.

ii.

Any research technique that is non-replicable or from which generalizations cannot be drawn.

iii.

One that moves away from extraordinary performance on standardized measures of intelligence or "creativity tests" and turns to the measurable technical and creative behaviour of students who are working toward the realization of their potential in a particular domain as well as the processing used by adults who have realized their potential in a particular domain

iv.

Assuming that non-traditional is meant in a positive way, it's anything creative or innovative.

v.

Anything that is not taught in a research methods course.

vi.

The least traditionally used method in gifted education is experimental design.

It's difficult to do with special populations, especially those not universally defined. 
vii.

The use of qualitative or

mixed methods design

that employs such theoretical frameworks as

critical theory,

queer theory,

feminist theory,

arts-based research, etc....

viii.

Investigation which does not include

pre-set method and analysis,

though it might be added to it.

ix.

Those heavily influenced

or borrowed from other disciplines.

$\mathrm{x}$.

All kinds of research are

embraced today.

xi.

I am not really sure

there is such a thing.

II

Case study

Action research

Grounded theory

Illuminative Evaluation

\section{III}

What do you consider to be the specific benefits derived from employing non-traditional methodologies?

i.

Preoccupation with "finding objective truth" narrowed the field to the point

it was somewhat sterile.

Non-traditional methodologies

helped rescue the field - and may help to keep it alive. 
ii.

Original questions cannot always be answered by well established methodologies.

iii.

iv.

A different view of causality, which involves intention and persistence

beyond cost/benefit analysis.

\author{
Flexible \\ $\&$ adaptable \\ $\&$ tuned
}

to changing research situations

v.

They provide a different angle

to the picture.

Deepen and broaden our understanding

in ways traditional methods are not able.

vi.

Some non-traditional methods have been instrumental in increasing a researcher's respectful treatment of the persons being studied.

vii.

Knowing in a different way. Especially, in a way psychology disdains.

Psychology is such a conservative discipline, and it does not admit other ways of knowing into the paradigm of

what is true, what is known, what is considered. 
viii.

You get more reliable data, answer questions not to be answered with traditional methods.

ix.

The information disseminated appeals

to more stakeholders -

you do not have to be an academic

or a statistician to understand the topic.

Phenomenology

Photo elicitation

Content analysis

Thematic analysis

Critical theory

\section{IV}

What do you consider to be specific challenges?

i.

None.

ii.

It's hugely important,

that they be applied

rigorously

carefully

credibly, and

are carefully articulated.

iii.

These are not the techniques taught in graduate schools.

Nor or they the techniques with which colleagues are familiar.

It's more difficult getting research published that departs

from mainstream research.

iv.

No good questions

lead to no-good

methodology. 
Insufficient explanation

of the researcher

agenda for doing the research.

vi.

Takes more time to collect and analyze the data and the investigator has to be more aware of biases

vii.

The biggest challenge is telling a convincing story and communicating it effectively.

viii.

For a student, there could be some risks in attempting innovative research.

ix.

\section{Reviewers}

who don't know what the heck they are talking about who want practical examples in a theoretical piece, who want a long methodology section in an arts-based piece, who cannot understand what a poetic basis of mind is, who haven't read anything but quantitative empirical pieces. I could go on.

\section{Archival \\ Ethnographic \\ Practical Inquiry \\ Evaluation Research}

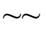

\section{V}

What are your hopes in employing such a methodology?

i.

To get deeper than the traditional test and analysis method 
ii.

To get more knowledge about various variables, and improve gifted education.

iii.

I study creativity.

If we're going to get any new insights

or new measures

or do anything that goes beyond what we already know, it has to be done creatively.

So many people who study creativity are happy to rely on the same old measures, which is a little ironic to me.

iv.

To be able to make an original contribution to the field.

V.

Biography is both

analytical and imaginative.

It is a powerful tool

for understanding the particular and for making inferences.

vi.

There are other ways of seeing, some people come from the arts, and "know" in a different way. I wanted people in the field to understand this.

vii.

That others will see its utility and adapt it for their own research

Biographical

Historical Analysis

Narrative Methods

SEM

Arts-based research 
VI

What are your fears?

i.

Fears?

ii.

iii.

Only that I live

too long

iv.

I fear getting bogged

down

bogged down

in tiny details \&

not being able to sort

sort the wheat sort the wheat

wheat from the chaff

v.

The use of the poetic

method has led

to some very bad

poems

vi.

The editor of on what he called "qualitative light" vs. "qualitative good."

"Light" was anything that attempted to be alternative, and he publicly disparaged these attempts.

This left me very disappointed in the possibility

for innovation in the way of knowing in our field.

vii.

That it appears

less solid than

more accepted

research.

That it is less solid

than more accepted

research. 
viii.

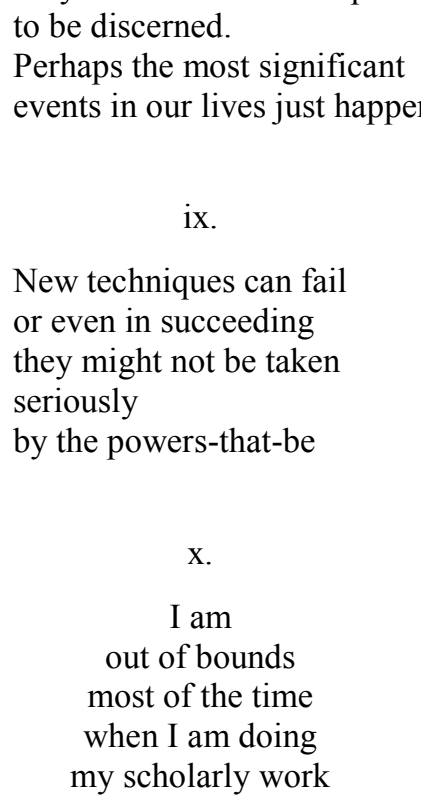

\section{References}

Aphorism. (2001). In D. Harper (Ed.), Online etymology dictionary. Retrieved January 28, 2009, from http://www.etymonline.com/

Atwood, M. (2006). The tent. Toronto, ON: McLellan and Stewart.

Barone, T. (2008). How arts-based research can change minds. In M. Cahnmann-Taylor \& R. Siegesmund (Eds.), Arts-based research in education: Foundations for practice (pp. 28-49). New York: Routledge.

Card, O. S. (1985). Ender's game. New York: Tor.

Eisner, E. W. (2005). Reimagining schools. The selected works of Eliot W. Eisner. New York: Routledge.

Field. (2005-2007). New Oxford American Dictionary, Version 2.0.2 (51.4) [Software]. Apple Inc.

Lakoff, G., \& Johnson, M. (1980). Metaphors we live by. Chicago: Chicago University Press.

Lakoff, G., \& Johnson, M. (1999). Philosophy in the flesh: The embodied mind and its challenge to Western thought. New York: Basic.

Leggo, C. (2004). Tangled lines: On autobiography and poetic knowing. In A. L. Cole, L. Neilsen, J. G. Knowledg, \& T. C. Luciani (Eds.), Provoked by art: Theorizing arts-informed research (pp. 1835). Halifax, NS: Backalong Books.

Subvert. (2005-2007). New Oxford American Dictionary, Version 2.0.2 (51.4) [Software]. Apple Inc.

\section{Author's Note}

Correspondence concerning this article should be addressed to Pamela Richardson, Faculty of Education, 2125 Main Mall, Vancouver, BC V6T 1Z4. Email: pamkela@gmail.com 